Review article

Section: Nutrition Research

\title{
The Dose Makes the Poison: Sugar and Obesity in the United States - a Review
}

\author{
Samir Faruque, Janice Tong, Vuk Lacmanovic, Christiana Agbonghae, Dulce M. Minaya, Krzysztof Czaja*
}

\author{
Veterinary Biosciences \& Diagnostic Imaging, College of Veterinary Medicine, University of Georgia, \\ 501 D.W. Brooks Drive, Athens, GA 30602, USA
}

Key words: sugar, obesity, sugar consumption, BMI, childhood obesity, adult obesity

Two-thirds of the US population is either overweight or obese. Obesity is one of the major drivers of preventable diseases and health care costs. In the US, current estimates for these costs range from $\$ 147$ to $\$ 210$ billion per year. Obesity is a multifactorial disease: genetics, lifestyle choices, metabolism, and diet. Low-fat diets have been suggested as the key to weight management. However, over the past 30 years, the calories from fat in people's diets have gone down, but obesity rates keep climbing. Evidence suggests that diets high in added sugar promote the development of obesity. However, the impact of sugar consumption on weight gain and body fat accumulation remains a controversial topic. Therefore, the aim of this review is to provide basic framework information about the prevalence of obesity and sugar consumption in the US over the last five decades. We also review the process by which sugar is converted to fat and stored in the human body. The relationship between sugar consumption and obesity was analyzed using United States Department of Agriculture (USDA) Sugar and Sweetener Outlook data, and obesity prevalence was analyzed using data from the Centers for Disease Control and Prevention (CDC). The analysis revealed a reduction in sugar consumption concurrent with a slowing down of the annual rate of increase of obesity. However, although the data show that the sugar consumption trend is going in the right direction (declining), the US population still consumes more than $300 \%$ of the recommended daily amount of added sugar.

OBESITY EPIDEMIC: THE ELEPHANT IN
THE ROOM

\section{What exactly defines obesity?}

Obesity was first included in the international lists of diseases and causes of death in 1948 [WHO, 1948]. Currently, according to the Obesity Medicine Association obesity is defined as "a chronic, relapsing, multifactorial, neurobehavioral disease, wherein an increase in body fat promotes adipose tissue dysfunction and abnormal fat mass physical forces, resulting in adverse metabolic, biomechanical, and psychosocial health consequences." Therefore, better understanding of obesity as a disease would not only help people be more mindful and work towards a balanced daily diet on the personal level but would also improve the effort in curbing obesity on the national and global level.

Compared to the data from 1960 to 1962 from the National Health Examination Survey, there has been an overall increase in the prevalence of obesity in the United States. As of 2014, the age-adjusted prevalence of obesity in the United States was $35.0 \%$ for men and $40.4 \%$ for women among adults aged 20 to 74 [Flegal et al., 2016]. Similarly, the prevalence of obesity in children and adolescents has steadily risen in the past decades, surging from 5.2\% (in 1971-1974) to $17.2 \%$ (in 2013-2014) [Fryar et al., 2014]. Consequently, obesity in children and adolescents was referred to as an "epi-

\footnotetext{
*Corresponding Author: E-mail: czajak@uga.edu (K. Czaja) individuals of different heights or body build may have simi-

demic" by the American Academy of Pediatrics Committee on Nutrition [Caprio \& Genel, 2005].

A first step in treating obesity is understanding what it is and how can it be measured. Throughout the years numerous methods have been developed and tested to accurately measure adiposity in order to diagnose obesity. Different from adults, practicality is a major deciding factor in choosing an appropriate measurement method for children because adhering to the testing protocols can be a challenge. Additionally, certain detailed body-composition measuring methods are based on adult models, and thus not suitable to be used on children [Alonso et al., 2018].

Currently, body mass index (BMI) is the most widely used method for diagnosing and staging obesity because it is more practical and easy to obtain compared to other methods. BMI estimates adiposity based on height and weight. The BMI data presented in the National Health Examination Survey are defined as weight in kilograms divided by height in meters squared. A high BMI is generally indicative of a high fat mass accumulation. Table 1 provides a breakdown of weight classification based on BMI [CDC, 2016]. Assessment of obesity in children and adolescents is commonly done by plotting BMI on a standard growth chart with defined BMI values and cut-off points relative to age and gender. Overweight is defined as BMI at or above the $85^{\text {th }}$ percentile of the sex and age group, while obesity is defined as at or above the $95^{\text {th }}$ percentile.

The accuracy of using BMI is often questioned because 
TABLE 1. Weight classification based on BMI measurements $\left(\mathrm{kg} / \mathrm{m}^{2}\right)$.

\begin{tabular}{l|c}
\hline \multicolumn{1}{c|}{ BMI } & Weight classification \\
\hline $\mathrm{X}<18.5$ & Underweight \\
$18.5<\mathrm{X}<25$ & Normal \\
$25<\mathrm{X}<30$ & Overweight \\
$30<\mathrm{X}<35$ & Class 1 Obesity \\
$35<\mathrm{X}<40$ & Class 2 Obesity \\
$\mathrm{X}>40$ & Class 3 Obesity \\
\hline
\end{tabular}

Data taken from the National Health and Nutrition Examination Surveys.

lar BMI values, yet different proportions of total body fat [Dietz \& Bellizzi, 1999]. Because BMI is an indirect measure of the amount of tissue mass in an individual to then categorize that person, it is possible to misclassify individuals as BMI does not differentiate fat mass from lean mass [Romero-Corral, 2008]. Adult individuals who seem to have more body fat and decreased muscle mass may be classified as normal while lean individuals with high muscle mass, but low body fat percentage may be classified as obese [Rothman, 2008]. In addition, an assessment by the International Obesity Task Force (IOTF) showed that in order to circumvent such problem when using the BMI to classify children and adolescents, several factors must be considered. For the cut-off point used to define obesity to be valid, the growth chart must incorporate different ethnic, sex, and age groups to account for the variations in percent body fat with the same BMI. Prior undernutrition should also be taken into account [Dietz \& Bellizzi, 1999]. Studies have shown that among short children, increased weight-for-height may be the result not of excessive body fat but rather lower body fat accompanied by greater lean tissue or lean tissue hydration [Trowbridge et al., 1987].

Besides BMI, other anthropometric measurements such as Waist circumference (WC), Waist to Hip ratio (WHR), Waist to Height ratio (WHtR), skinfold thickness, and bioelectrical impedance are indirect physiological measurements of central obesity. WC has been found to be correlated with the risk of acquiring chronic conditions such as type 2 diabetes. However, WC measurements are usually restricted to individuals labeled as normal or overweight so predicting disease risk using WC is generally not useful in patients with obesity [National Heart, 2013]. Men with a waist circumference above $102 \mathrm{~cm}$ and women with a WC above $88 \mathrm{~cm}$ are at a higher risk of developing an obesity-related disease. WC cut-off points usually apply to adults in all ethnic and racial groups. However, if the individual is very short or has a BMI above 30, WC cut-off points as a predictor for disease may not be as accurate. Although WC can be monitored with BMI, patients can also keep track of their WC independently as it can provide an estimate of changes in abdominal fat.

WHR and WHtR incorporate WC measurements and serve as additional measurements of body fat distribution. WHR is calculated by dividing WC by hip circumference. Similarly, WHtR is calculated by dividing WC by height. For these measurements, factors such as posture, stomach contents at the time of measurement, and tightness and type of tape may introduce measurement error [WHO, 2011]. Combining two or more of these methods could provide the most accurate classification [Liu et al., 2011]. Skinfold thickness is an anthropometric method that uses the total sum of skinfold to estimate body fat based on developed prediction models. This method uses a special caliper to measure subcutaneous fat at sites such as triceps, biceps, the subscapular region, abdomen, and thigh [Hu, 2008]. Equations used to estimate body fat from skinfold thickness are highly population specific and strongly dependent on age. The latter factor is because subcutaneous adipose tissue distribution changes during maturation. A notable limitation of this method is that skinfold thickness cannot be accurately measured in morbidly obese patients, both children and adults [Goran, 1998; Sarria et al., 1998]. Bioelectrical impedance analysis calculates fat mass by transforming total body water into fat-free mass. Compared to the hydration of fat-free mass in adults being relatively constant at approximately $73.2 \%$, that of children varies. The variation complicates the conversion of total water into fat-free mass, imposing a limitation on the bioelectrical impedance analysis method [Talma et al., 2013].

Direct measure methods such as densitometry, Dual-energy X-ray absorptiometry (DXA), and X-ray computerized tomography are preferred for measuring visceral adipose tissue (VAT), yet are costly, and less practical for wide-scale use. Densitometry, also called underwater or hydrostatic weighing, uses measurement of total body density to estimate body composition. The method is based on the principle that fat is less dense than water and, consequently, an individual with more body fat will have lower body density. Densitometry weighs the subject in air as well as underwater. The recorded measurements are then used to estimate body volume, body density, and percent body fat using an established formula [Hu, 2008]. Although often referred to as the "gold standard" of measuring body composition, densitometry faces two limitations when applied to children. Besides the strict and timeconsuming testing procedure that proved to be difficult for young subjects, densitometry also requires additional knowledge on densities of fat and fat-free masses in children, which are influenced by age, gender, and ethnicity [Lohman, 1986].

DXA is a commonly used standard to study VAT volume. DXA scans provide 2-dimensional images of different tissues and organs [Silver et al., 2010]. Photons are produced that travel through bone, fat, and non-bone lean tissue. Unique elements in each type of tissue, such as calcium and phosphorus in bone, allow for visualization and analysis of each tissue type. DXA scans typically last between 5-20 min and are advantageous because body fat distribution and regional bone mineral density can be determined simultaneously [Rothney et al., 2009]. Similar to densitometry, DXA has limitations. The maximum weight and width of the scanning area are approximately $136 \mathrm{~kg}(300 \mathrm{lb}$.) and $60 \mathrm{~cm}$, respectively [Brownbill \& Ilich, 2005]. To accommodate heavier subjects, iDXA was introduced with expanded capacity: $400 \mathrm{lb}$. and $66 \mathrm{~cm}$. However, even with this improvement, morbidly obese individuals who are above the iDXA scanner weight limit are still not covered, making the total body composition of such subjects difficult to attain [Rothney et al., 2009]. In addition, 
studies using animal carcasses have shown that confounding factors such as the animal size, the equipment, and the operation mode or calibration equation may affect the accuracy of DXA estimates [Brunton et al., 1993].

X-ray computerized tomography (CT) could be used as a diagnostic imaging technique for obesity but CT scans are hazardous to patients because of the ionizing radiation given off by the scans. For this reason, CT is typically limited to diagnosing patients with acute illnesses [Poonawalla et al., 2013]. T1-weighted magnetic resonance imaging (MRI) is a less harmful alternative to CT scans because it does not expose patients to any ionizing radiation. However, separating VAT from subcutaneous adipose tissue and non-adipose tissue by MRI is a costly and time-consuming process. This process is also highly likely to result in a systematic error. While small-scale research studies may use CT and MRI to measure obesity, anthropometric measures like BMI are still more widely used [Poonawalla et al., 2013].

In conclusion, obesity is a chronic disease manifested by an increase in body fat accumulation and resulting in adverse metabolic and psychosocial health consequences. Because recent studies show that body adiposity can be increased without dramatic increase in body weight by consumption of high-sugar diets [Do et al., 2018; Sen et al., 2017], more specific methods determining body fat content described in this review should be used more frequently in diagnostics of obesity. This will allow us to identify metabolically obese normal weight people with normal BMI and metabolic syndrome [Ruderman et al., 1998].

\section{Today's overweight children. Tomorrow's obese adults?}

Pediatric obesity is associated with increased prevalence of cardio-metabolic risk factors that predict early onset of serious diseases, such as hypertension and diabetes [Skinner et al., 2015]. Prevalence of the metabolic syndrome in obese adolescents may be as high as 30\% [Daniels, 2009]. The number of additional cardiovascular events attributable to excess weight in adolescents is expected to be $>100,000$ by 2035 , in the United States alone [Cote et al., 2013]. This prediction is plausible since approximately $75 \%$ of obese children have advanced vascular age similar to that of a 45-year old adult due to altered cardiac structure and function, which includes higher epicardial fat deposition, diastolic and systolic dysfunction at both rest and exercise, and greater atrial stiffness [Cote et al., 2013]. Consequently, the risk of having both fatal and nonfatal coronary heart disease event in adulthood is significantly elevated for children and adolescents with BMI higher than average, according to a cohort study on children aged seven to thirteen that evaluated the association between childhood BMI and adult coronary heart disease [Baker et al., 2007].

Growth and development during adolescence is associated with normal increase in insulin resistance [Daniels, 2009]. However, if the insulin resistance is further exacerbated by obesity, it can result in deleterious consequences, notably glucose intolerance followed by type 2 diabetes mellitus. The decreased insulin sensitivity and increased circulating insulin levels observed in many obese children often persist through the transition into young adulthood. Another metabolic complication observed in obese children and adolescents is dyslipidemia; more specifically, triglyceride levels are increased while high-density lipoprotein cholesterol level is decreased, often referred to as atherogenic dyslipidemia. The condition is known to accelerate atherosclerosis, marked by the buildup of plaque in the arteries that limits the flow of oxygen and further contributes to the coronary heart disease associated with pediatric obesity discussed earlier [Daniels, 2009]. Preventive and early intervention measures must be taken to prevent the comorbidity and mortality associated with obesity in children and adolescents. Besides having adverse effects on the well-being of the child, obesity may lead to other complications in the long run. Obese children and adolescents have a higher probability of being obese as adults and increased risk of obesity-related comorbidities in adulthood, i.e. cardiovascular disease, premature mortality [Reilly et al., 2003]. Furthermore, individuals who were obese as a child showed elevated morbidity and mortality in adulthood despite losing the extra weight as adults [Deckelbaum \& Williams, 2001].

Studies have shown that the energy imbalance causing obesity is in fact affected by other contributing or predisposing factors [Baranowski \& Taveras, 2018]. Possible factors include obesogenic infectious agents, toxic chemicals, genetic influences, epigenetic influences, the gut microbiome, brown or beige fat, and prenatal and early childhood factors (such as the breast milk hormones and adipocytokines) [Fields et al., 2017]. These factors alone can influence energy balance or interact with one another to bring out a wide range of outcomes. To further complicate the equation, the contributing factors can also vary based on the stage of maturation. The interplay between obesity and underlying environmental factors is also observed, where different socioeconomic or cultural factors can make certain subpopulations more susceptible to obesity [Seidell \& Halberstadt, 2016]. On a daily basis, family environment contributes to the increased prevalence of obesity through food supply/caloric intake and patterns of physical activity [Deckelbaum \& Williams, 2001]. The existence and corresponding influence of contributing and predisposing factors were reflected in the result of obesity preventive trials. In an effort to curb the prevalence of adolescent obesity, numerous prevention trials (such as educational, behavioral, and health promotion interventions) have been designed and implemented to emphasize healthy diet, increase physical activity, decrease sedentary behaviors, and sleep. According to the Cochrane review of childhood obesity prevention research that evaluated 55 different studies, the majority of existing interventions had little to no effect on decreasing adiposity of the subject, mainly due to failure to consider and incorporate contributing or predisposition factors [Waters et al., 2011].

\section{Prevalence of obesity}

The National Health and Nutrition Examination Survey (NHANES) program of the National Center for Health Statistics used BMI as an indicator for the prevalence of obesity in the United States beginning in 1960. Although the crosssectional health examination surveys began in 1960, it was not until 1999 that the NHANES continued without breaks 
between each survey period [Flegal et al., 2016]. Information prior to that was collected by the National Health Examination II and III: 1963-1965 and 1966-1970, along with three less consistent NHANES I-III: 1971-1974, 1976-1980, and 1988-1994. The evolution of the national survey was mainly constituted by the shift in focus from growth and development to nutrition and health, the additional collection of environmental exposures and infectious diseases data, and the gradual inclusion of younger age groups as well as more ethnically diverse population groups.

The participants in the NHANES survey were selected using a complex, stratified, multistage probability cluster sampling design [Flegal et al., 2016]. Prior to the examination, a household interview was conducted in order to record the age of the participants. A mobile examination center with standardized techniques and equipment was used for all of the surveys. For every NHANES cycle, heights and weights of participants were measured by trained health technicians as part of the anthropometry component. Pregnant women and observations for participants missing valid height and weight measurements were excluded from the survey analysis [Flegal et al., 2016]. The surveys conducted by NHANES may have been subject to sampling error or non-sampling error. The surveys were also limited to detecting only small changes in the prevalence of obesity, especially among subgroups that were defined by sex, age, race, and ethnicity [Flegal et al., 2010].

To compare data across surveys, the data for subjects aged 20-74 were age-adjusted by direct method to the U.S. population estimates in 2000. The adult age groups were 20-39, 40-59, and 60-74 years old. For the data collected in the surveys, BMI was defined as indicated in Table 1. The National
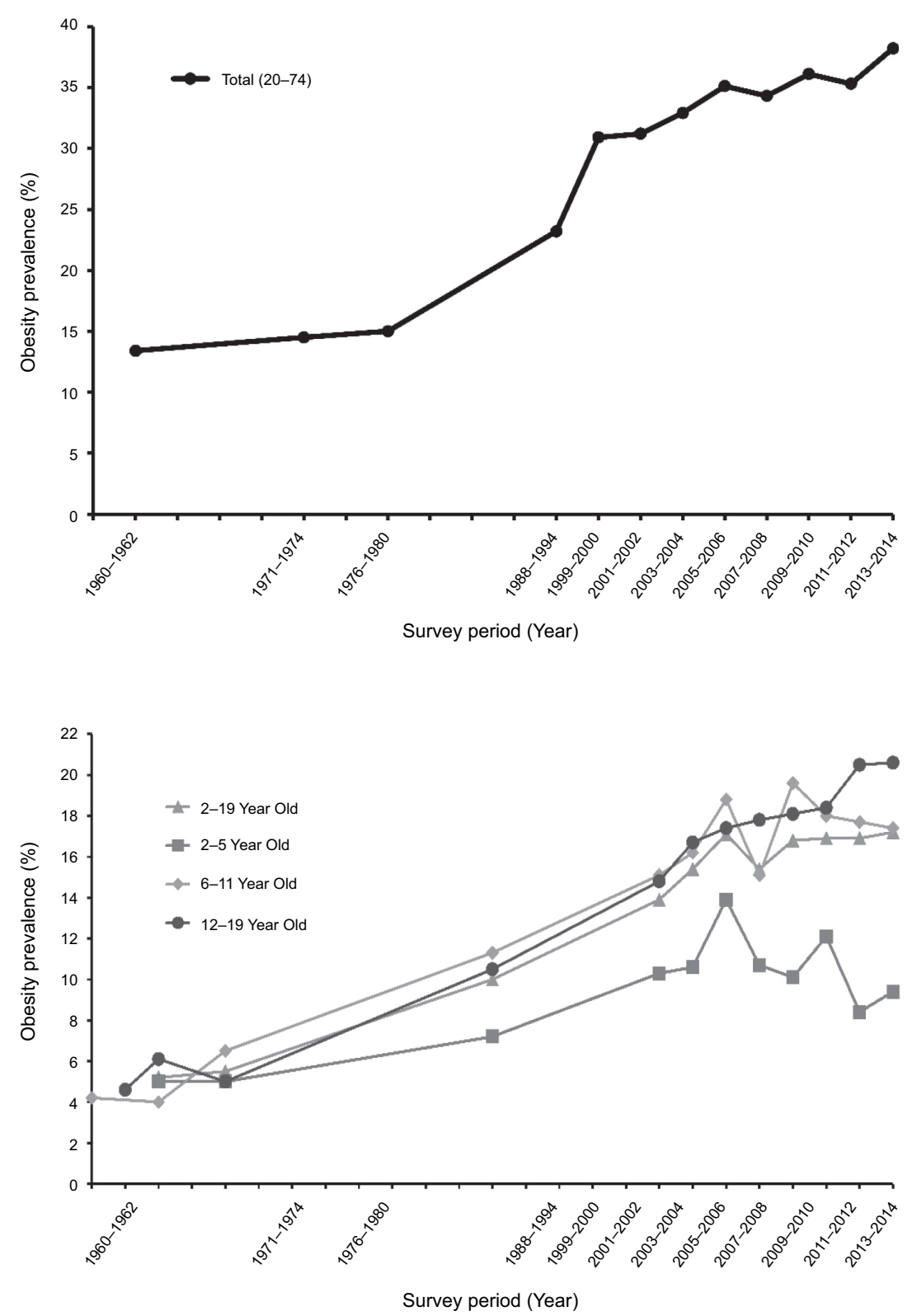

FIGURE 1. Prevalence of obesity in the United States. Top panel shows adult obesity level based on survey data collected 1960-2014. The bottom panel shows the prevalence of obesity in children and adolescents 1963-2014. Data from the National Health and Nutrition Examination Surveys. 
Health Examination Survey (NHES) cycle I (1960 to 1962) included adults age 18-79. The National Health and Nutrition Examination Survey (NHANES) cycles I and II did not include adults over the age of 74 so trend estimates are made for adults between 20 and 74. Sample sizes for each of the surveys varied. NHES and NHANES also grouped data by race. Survey data were collected between 1960 and 2014 (Figure 1) [Flegal et al., 2010].

The US Centers for Disease Control and Prevention (CDC) BMI-for-age growth chart was used to determine obesity in participants aged 2-19. Similar to NHANES, the CDC growth chart has been revised to better reflect the populations [Kuczmarski, 2002]. The 1977 version of the growth chart used data from NHES II, NHES III, and NHANES I. The old chart was only applicable to prepubescent boys from 90 to $145 \mathrm{~cm}$ in height and girls from 90 to $137 \mathrm{~cm}$. The revision of the growth chart was conducted in 2000, using all NHES and NHANES along with improved statistical smoothing procedures. The revision replaced the limited chart with the 2000 CDC BMI-for-age charts, applicable to all children ranging from two to twenty years. The pattern of the BMI curve shows a rapid increase from birth to the eighth month, then decrease until around six years of age, followed by a rebound, as seen in Figure 2. Adiposity rebound is the age where body masses begin to rise after reaching a minimum. Studies have shown that the younger the age at which the curve hits nadir, the greater the likelihood of higher level of adiposity during adolescence and early childhood [Kuczmarski, 2002]. Additionally, children at higher BMI percentiles tend to achieve earlier adiposity rebound.

Comparison of consecutive NHANES data have showed an increase in adult as well as childhood obesity in the United States. From 1960 to 1962, the percentage of overweight adults in the United States was $31.5 \%$ while the percentage of obese adults was $13.4 \%$ [Ogden \& Carroll, 2010]. From 2013 to 2014, the percentage of overweight adults remained stable at $31.9 \%$ while the percentage of obese adults increased to $38.2 \%$ [Fryar et al., 2016]. Between 1960 and 2014, the obesity level in the United States increased more than $100 \%$ (Figure 1, top panel). The increase in pediatric obesity is most evident in the 12-19 age subgroup (Figure 1, bottom panel). From 2001 to 2014, the prevalence of obesity in the 2-5 age group decreased by $1.2 \%$ while that in 6-11 year increased by $1.2 \%$. The overall increased prevalence was mainly contributed by the 12-19 year old group, which experienced a dramatic 3.9\% surge [Ogden et al., 2016].

Although the percentage of both adult and childhood obesity has continued to rise during the past decades, the rate of increase has actually decreased. Four studies focusing on U.S. data showed stability or a leveling off in childhood obesity prevalence. The tendency towards stabilization of childhood obesity in the U.S. is analogous to that of Australia, Europe, and Russia [Rokholm et al., 2010]. As can be seen in Figure 2, the turning point toward stabilization in adult and childhood obesity both appeared to be predominantly in the early 2000s.

Of the environmental factors that contribute to obesity, sugar consumption, especially in the form of sugar-sweetened beverages, has gained the attention of epidemiologic studies
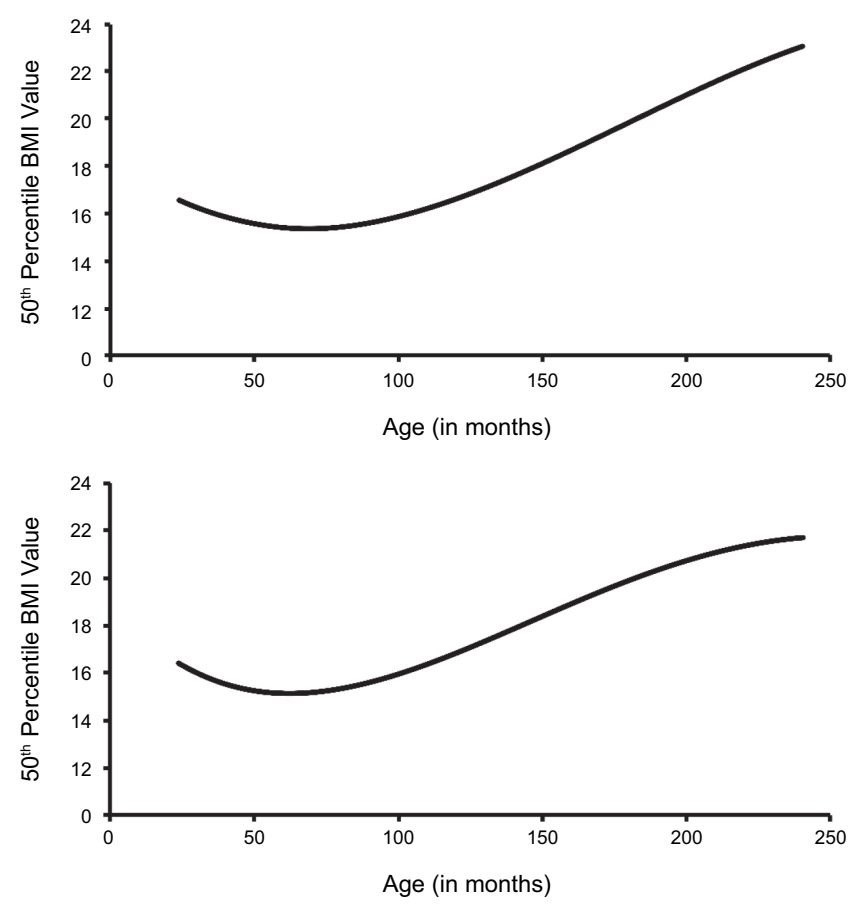

FIGURE 2. Average BMI-for-age charts for two to twenty-year-old (A) males and (B) females. Created from the CDC 2000 Growth Charts. The start of adiposity rebound is observed at 6 years of age in both male and female subjects.

in the past several decades. Soft drinks constitute the leading source of added sugar in everyday diet [Ludwig et al., 2001]. Findings from large cross-sectional studies along with cohort studies have shown a positive association between increased intake of sugar-sweetened beverages and weight gain as well as obesity in both children and adults [Malik et al., 2006].

The US population consumes more than $300 \%$ of daily recommended amount of added sugar!

Several theories attempt to explain the rising levels of obesity as described in the previous section. One posits that it is simply a balance of calorie intake and expenditure, with the former increasing to unprecedented levels and the latter reaching all-time lows with more sedentary lifestyles. Another concludes that increased amounts of fat consumption may induce obesity and its related comorbidities. These theories have validity, but their simplicity does not entertain the nuances or subtleties of the causes of obesity as they may disregard several factors and/or mechanisms that may be especially responsible for rising obesity rates. Altered patterns of sugar consumption may play a role as preceding and concurrent changes in sugar consumption rates in the United States since the 1970's occur simultaneously to changes in obesity rates.

In the United States, sugar consumption has been recorded and tracked by surveyed accounts conducted by the National Center of Health Statistics (NCHS) in the Center of Disease Control (CDC) and by deduction from imports and deliveries of sugar, which was done by the United States Department of Agriculture (USDA) [CDC, 2012; USDA, 2017]. The American Heart Association (AHA) recommends limiting daily sugar consumption to $25 \mathrm{~g}$ /day for an adult woman and $37.5 \mathrm{~g} /$ day for an adult man [Johnson et al., 2009]. These 
recommendations were derived using the concept of discretionary calories. Discretionary calories was a concept developed to aid people in meeting their nutritional requirements while avoiding excess caloric intake. It is calculated by estimating a person's caloric need to meet nutrient requirements and subtracting this from their caloric need to maintain a stable body weight. The goal of the recommendation is to help people maintain a healthy body weight, decrease their risk of cardiovascular disease and other comorbidities, and meet their nutritional requirements [Johnson et al., 2009].

The NCHS uses the National Health and Nutrition Examination Survey (NHANES) to determine the sugar consumption per person. This survey assesses food and beverage consumption through an interview based on the self-reported recall of dietary information from a respondent from the last 24 hours [CDC, 2012]. These values are then converted into numerical values for caloric energy intake [Blair et al., 1992]. Although the NHANES has been used frequently to determine the per capita sugar consumption, it has methodological limitations. The majority of the caloric intake measured from this survey were found to be physiologically unlikely due to misreporting, suggesting that it may have a poor ability to estimate population trends in caloric intake, therefore making analyses using data from these surveys extremely limited in utility [Archer et al., 2013].

The Economic Research Service of the USDA has compiled information and deduced the annual per capita consumption of sweeteners, including refined cane and beet sugar, high fructose corn syrup (HFCS), and other sweet- eners (molasses, honey, etc.) annually since 1970 [USDA, 2017]. The values for annual sugar consumption were found by estimating per capita sweetener deliveries for domestic food and beverage use at the market level and subtracting losses between the processing of the sugar to the ingestion by the consumer.

Data for the deliveries of the three categories of refined cane and beet sugar, high fructose corn syrup (HFCS), and other sweeteners (honey, molasses etc.) were gathered using different sources. Refined sugar data comes from the USDA's Farm Service Agency's Sweetener Market Data publication, where all US and Puerto Rican sugar beet processors, sugarcane millers, and cane sugar refiners report their information to the FSA in accordance to the Farm Security and Rural Investment Act. The ERS estimate HFCS deliveries with data from "various industry contacts and consulting firms" including the US Census Bureau. The "other" sweetener category includes delivery estimates from honey, molasses and syrups. Honey deliveries were estimated using production and stock data from the USDA's National Agricultural Statistics Service's (NASS) annual report on honey and the US Bureau's import and export of honey data, and the deliveries of other sugars are assumed to be about the same as maple syrup, which is also reported by NASS and US Bureau [Haley et al., 2005].

Sources of loss include loss from market to retail/institutional level, loss from retail/institutional to the consumer level, and loss at the consumer level, which includes uneaten foods and spoilage. ERS calculated the adjustment for loss

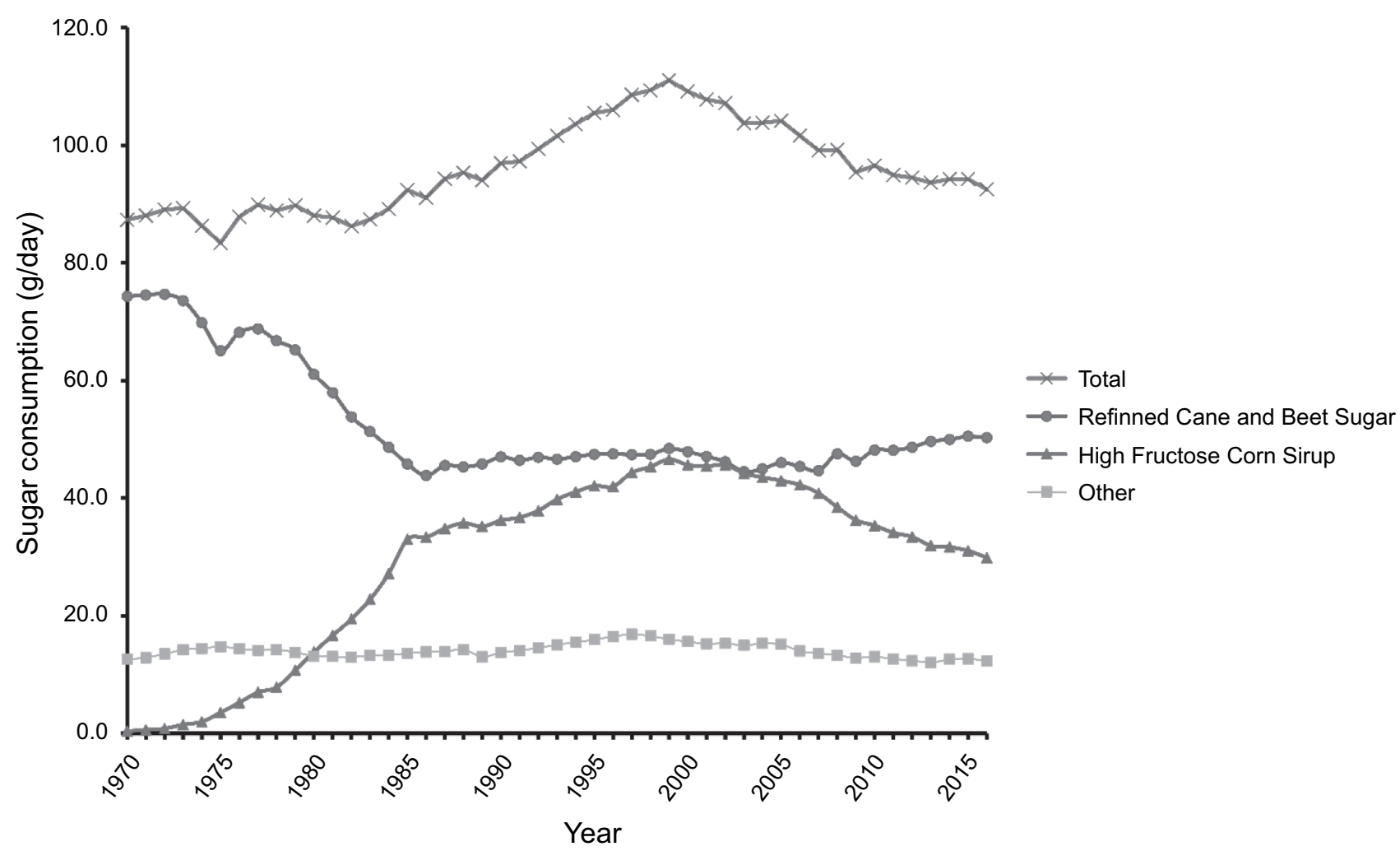

FIGURE 3. Per capita sugar consumption for total, refined cane and beet sugar, high fructose corn syrup, and other sugars (molasses, honey, etc.) in grams per day from 1970 to 2016. Total sugar consumption peaks in the year 1999 with 111.0 g/day and has declined slowly afterwards. Increase and subsequent decline of HFCS most likely plays major role in that trend. Data collected from the USDA Economic Research Service. 
at these levels using analyzed survey data from the Food and Drug Administration [Kantor et al., 1997].

By accounting for these sources of loss, the per capita consumption of sugar in grams per day was determined [USDA, 2017]. Since these estimations were made using food availability data and its loss at varied stages, they provide alternative data that may better represent per capita sugar consumption in the United States, analyzed below.

Total sugar consumption increased from 1970 to 1999 , peaking in 1999 at 111.0 grams per day (Figure 3). Since 2000, total sugar consumption has had a steady state of decline to about $92.5 \mathrm{~g} /$ day in 2016. Refined sugar levels declined drastically from $59.8 \mathrm{~g} /$ day (1970) to $35.3 \mathrm{~g} /$ day (1986) and stayed steady, HFCS drastically increased from $1.0 \mathrm{~g} /$ day (1970) to about $37.5 \mathrm{~g} /$ day (1999) (Figure 3). Thus, the increase in total sugar consumption from 1970 to 1999 is likely due to the large influx of HFCS in the mid 1970's. After 2002, HFCS consumption dropped considerably to an estimated $24.0 \mathrm{~g} /$ day (2016), while consumption of refined sugar started to increase steadily and eventually leveled off in the last decade, with estimated levels at $40.5 \mathrm{~g}$ /day (2016). Other sources of sugar consumption have stayed steady since 1970 at around an estimated $14.1 \mathrm{~g} /$ day (Figure 3). Thus, the decline of total sugar consumption after 2002 can be attributed to the considerable decrease in the HFCS consumption [USDA, 2017].

The increase in total sugar consumption and, in particular, HFCS, roughly paralleled the increase in obesity in the United States, with some studies suggesting that it was causal [Bray et al., 2004; Havel, 2005]. With individual sugar consumption at levels over twice the recommended levels by the American Heart Association of $36 \mathrm{~g} /$ day for men and triple the recommended dose $20 \mathrm{~g} /$ day for women, the link between sugar consumption and obesity is plausible [Johnson et al., 2009]. However, research conducted in animals has shown that the relationship between sugar consumption and obesity is more nuanced, suggesting that a decrease in sugar consumption since the year 2000 has not led to a decrease in obesity [Schulze et al., 2004]. Although conflicting studies demonstrate some uncertainty on this topic, it is plausible that sugar consumption may be a strong factor that has driven changes in obesity rates in the United States. However, on average, the US population still consumes more than $300 \%$ of the daily recommended amount of added sugar.

\section{HOW DOES TOO MUCH SUGAR MAKE YOU FAT?}

Although increases in obesity have been attributed to a multitude of factors including a lack of physical activity and an increase in food portion sizes, dramatic changes in sugar consumption as reported and described in the previous section is a prime candidate that may independently contribute to the rise of obesity [Marteau et al., 2015; Morris et al., 2015].

Sugars are widely found in our food environment and are typically consumed as a naturally occurring component of many foods or as additive, i.e. sweeteners ae sometimes added to foods during processing or preparation for consumption. A healthy, well-balanced diet contains naturally occurring sugars since monosaccharides like fructose and disaccharides like sucrose and lactose are integral components of vegetables, fruits, milk and milk-derived products, and grains. Thus, understanding the process by which ingested sugars are broken down and then converted to fat and stored in the human body is of utmost importance to appreciate the harm that excess sugar consumption can cause. Sugar is initially consumed orally primarily as either glucose, fructose, lactose, sucrose, and as the polysaccharide starch. A small yet significant amount of starch is converted into maltose by amylase in the oral cavity [Stenesh \& Stenesh, 1989]. These saccharides then move from the oral cavity to the stomach via the esophagus (Figure 4-A) [Marieb, 2001]. In the stomach, there is only partial digestion of sugars due to mechanical forces and low $\mathrm{pH}$ (Figure 4-A) [Miftahof, 2017]. The small intestine is where the majority of sugars are digested and absorbed. The important process of disaccharide hydrolysis occurs in the small intestine as well. Lactose is hydrolyzed by lactase whereas sucrose and maltose are hydrolyzed by sucrase and maltase respectively (Figure 4-A) [Levin, 1994]. The two primary monosaccharides: glucose and fructose, are then transported across the epithelium of the small intestine and into the circulatory system (Figure 4-A). Glucose crosses the apical membrane via a sodium-glucose symporter [Berne et al., 2010]. Before this movement of glucose and sodium into the epithelium, a $\mathrm{Na}^{2+}-\mathrm{K}^{+}$ ATPase creates a favorable electrochemical gradient for $\mathrm{Na}^{2+}$ by pumping it out of the epithelium [Saha et al., 2015]. Fructose crosses the apical membrane via a GLUT5 transporter, however the exact process as to how fructose crosses the basolateral membrane has not been elucidated [Berne et al., 2010].

Following movement across the epithelium, glucose and fructose move through systemic circulation as they pass non-hepatic and hepatic tissue. The fructose capturing enzyme fructokinase is found exclusively in hepatic and kidney tissue [Watson, 2014]. Fructokinase also has a twenty-fold greater affinity for fructose than glucose [Raushel \& Cleland, 1973]. Therefore, a majority of fructose is taken up by the liver and a majority of glucose bypasses hepatocytes and provides energy for non-hepatic tissue such as the brain and myocytes (muscle cells).

In the liver, both fructose and glucose are converted to an important intermediate; glyceraldehyde-3-phosphate (Figure 4-B). However, unlike glucose, fructose metabolism is not subjected to fructose kinase regulations. Therefore, energy status does not regulate fructose uptake by the liver and subsequent DNL, which means that a high level of consumed fructose enters the liver with little reaching the systematic circulation [Stanhope et al., 2013]. The increased rate of DNL induced by fructose generates fatty acids for hepatic triglyceride production and thus leads to postprandial hypertriglyceridemia. Fructose can yield greater amounts of fat when consumed in larger quantities than glucose [Berg et al., 2015]. Fructose consumption fosters an imbalance between hepatic lipid input and output, creating a net liver fat accumulation [Stanhope et al., 2013]. In addition, increased consumption of fructose leads to decreased secretion of insulin and leptin, hormones known to regulate energy homeostasis by decreasing food intake and increasing energy expenditure [Elliott et al., 2002]. 

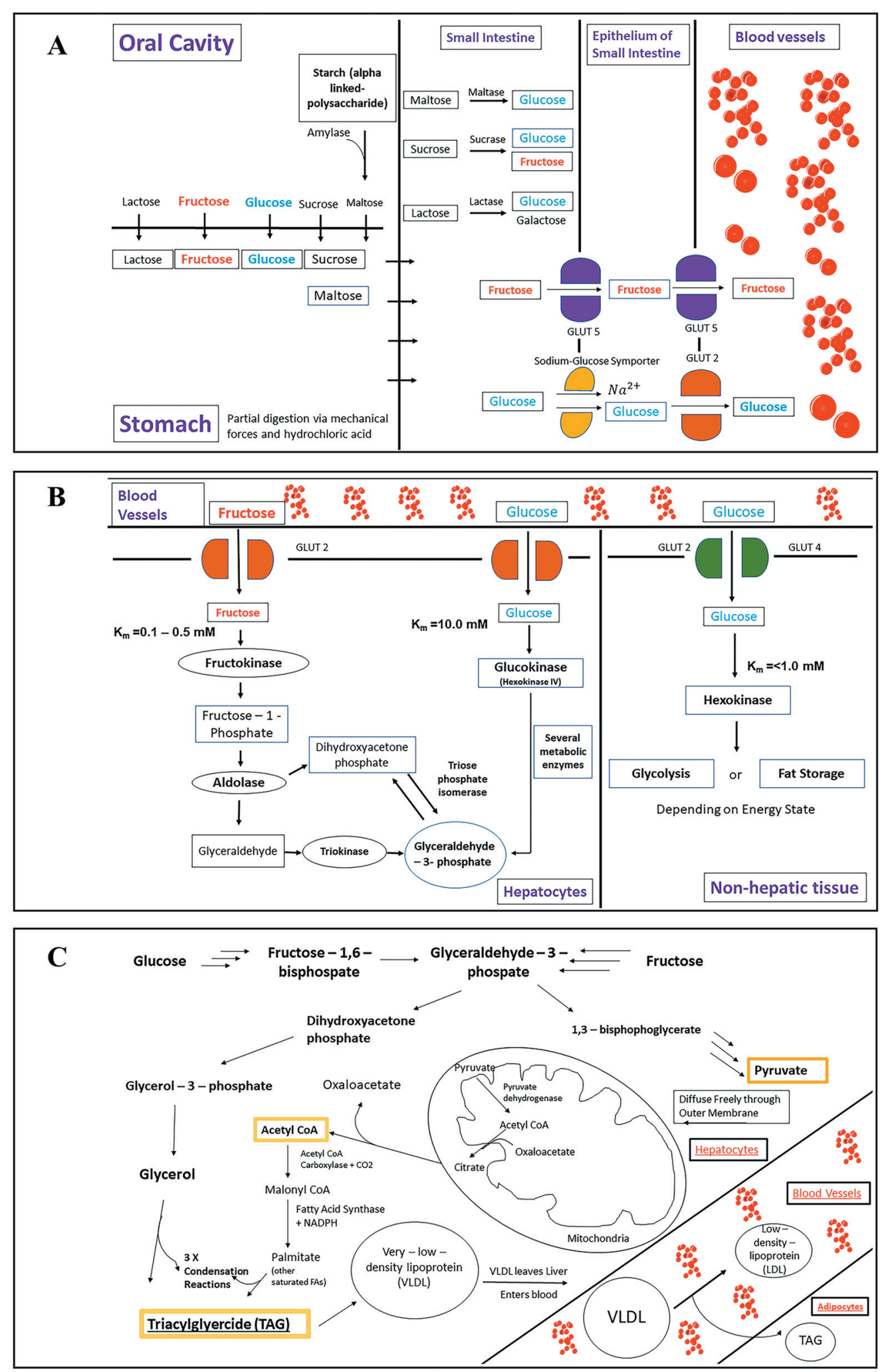

FIGURE 4. The sugars most commonly consumed are the monosaccharides glucose and fructose and the disaccharides sucrose, maltose, and lactose. Glycogen and starch are polysaccharides composed of the glucose disaccharide, maltose. The difference between glycogen and starch is that glycogen is more highly branched. A) Following ingestion of these sugars, they move down the esophagus into the stomach where there is minimal digestion. In the small intestine is where the majority of digestion is completed. Enzymes maltase, sucrose, and lactase all convert their respective disaccharides to their monosaccharide precursors. These sugars are then transported via channels to epithelial cells of the small intestine and ultimately to blood vessels. B) Fructose and glucose leave blood vessels and enter hepatic or non-hepatic tissue dependent on the affinities of those cells for the monosaccharides. Fructose almost exclusively moves into hepatic tissue due to fructokinase's high affinity (low Km) for the sugar. In hepatic tissue fructokinase is converted to glyceraldehyde and subsequently glyceraldehyde-3-phosphate both of which are involved in the process of glycolysis. C) The key steps in triglyceride synthesis shown in the pathway are the production of Acetyl CoA in the mitochondria which ultimately leads to the creation of fatty acids through a process of reduction, addition of the production of glycerol which serves as the backbone of triacylglycerides, and the production of TAGs via condensation reactions between glycerol and fatty acids. 
In either pathway the steps following the production of glyceraldehyde-3-phosphate lead to the formation of endogenous triacylglycerides (TAGs). Acetyl CoA, which produces the fatty acid chains for TAGs, is synthesized from the regular pathway of glycolysis. However, unlike in energy deficient states, Acetyl CoA is not fed into the citric acid cycle but instead forms palmitate and other saturated fatty acids. Glycerol, which forms the backbone of TAGs is produced from a diverging pathway that is produced by conversion of glyceraldehyde-3-phosphate to dihydroxyacetone phosphate by triose phosphate isomerase. This is followed by the conversion of dihydroxyacetone phosphate to glycerol-3-phosphate (Gro3P) by glycerol-3-phosphate dehydrogenase. Finally, glycerol is produced by the removal of a phosphate by glycerol-1-phosphatase (Figure 4-C) [Berg et al., 2015].

These endogenous TAGs are transported out of the liver by very low-density lipoproteins (VLDL) and travel through the blood stream binding to VLDL receptors on adipocyte surfaces. Once the VLDL particles are endocytosed, their cargo, which includes TAGs as well as cholesterol, are released via lysosomal degradation of VLDL membranes (Figure 4-C). Excess TAGs are then incorporated into existing lipid droplets found in adipocytes causing an increase in size of the droplet which triggers adipocytes to undergo hypertrophy [Berg et al., 2015; Stenesh \& Stenesh, 1989].

Glucose and fructose have different regional adipose distribution: fructose promotes lipid deposition in visceral adipose tissue, while glucose favors subcutaneous adipose tissue deposition [Stanhope et al., 2009]. Individuals who consumed highfructose diets showed increased hepatic de novo lipogenesis (DNL), postprandial triglycerides, insulin resistance, and markers or altered lipid metabolism [Basciano, et al., 2005].

\section{REDUCTION IN SUGAR CONSUMPTION MAY SLOW DOWN THE ANNUAL INCREASE OF OBESITY}

When comparing sugar consumption and obesity in the last half century, the data yields qualitative findings that show a trend indicative of sugar consumption's role in the obesity epidemic in the United States.

In order to analyze the relationship between sugar consumption and obesity, four variables need to be defined to describe the trends: obesity prevalence in percentage, sugar consumption per capita in grams per day, the annual change in obesity prevalence, and the annual change in sugar consumption per capita. The values of obesity prevalence and sugar consumption data are cited and described in the previous sections of this paper. The data was then used to estimate both the average obesity prevalence and average sugar consumption per capita for the following decades: 1970's, 1980's, 1990's, 2000's, and 2010's. The slope (rise over run) between these decades were then calculated, thus describing the respective annual rates of change (constant or average rate of change) per decade for those values. The slope is calculated by taking the differences in the average values between each of the decades and dividing them by the number of years elapsed, indicating how much obesity prevalence or sugar consumption either increased or decreased each year in their respective decades.
Figure 5 shows that sugar consumption per capita reached its peak in the 1990's and that obesity prevalence continues to grow, but at a slower rate since. In the 1970's and 1980's, sugar consumption increased drastically with an increasing pace reaching its peak in the 1990's; the annual rate of change for each decade were $+0.26 \mathrm{~g} /$ day and $+1.33 \mathrm{~g} /$ day, for 1970's and 1980's, respectively. In the 1990's and 2000's, sugar consumption fell, with the annual rate of change for those decades at $-0.08 \mathrm{~g} /$ day and $-0.91 \mathrm{~g} /$ day, respectively. Adult obesity prevalence also increased in the 1970's, 1980's, and 1990's, each decade with a higher annual rate of change of $+0.05 \%,+0.82 \%$, and $+0.97 \%$, respectively. In the 2000 's, obesity increased by at a lower rate of only $+0.365 \%$ each year, indicating a slowing in the annual rate of change in adult obesity. Childhood obesity followed a similar trend (Figure 5).

There are two main takeaways from the described data that suggest a strong link between sugar consumption and the obesity epidemic in the United States. First, sugar consumption's drastic rise from the 1970's to the 1990's is followed by the subsequent exponential growth in obesity prevalence from the late 1970 's to the 2000's, and, even more indicative of this association, the drop in sugar consumption from the 1990's to 2010's preceding a slowing of the annual increase in obesity prevalence in the 2000's. Second, this general trend observed shows that over time, obesity prevalence may change as a response to changes in sugar consumption per capita, indicating a positive correlation between sugar consumption and obesity prevalence qualitatively observed (Figure 5).

\section{SUGAR CONSUMPTION HIJACKS THE GUT-BRAIN COMMUNICATION SYSTEM: GUT RESIDENTS' LARGELY AT FAULT}

Obesity has been recognized as a low-grade, chronic inflammatory disease [Ouchi et al., 2011]. Consumption of energy-dense diets strongly relates to obesity, induces detrimental changes in the gut microbiome, and triggers inflammation in the gut-brain neural communication [Sen et al., 2017; Vaughn et al., 2017]. Sensory information from the stomach to the brainstem is carried by gastric vagal afferents [Altschuler et al., 1989; Berthoud \& Powley, 1992], and the significance of the integrity of this system for the control of ingestive behavior has been previously described [Norgren, 1983; Ritter, 2004; Schwartz, 2000]. Approximately $70-80 \%$ of vagal fibers are sensory fibers whose cell bodies are located bilaterally in the inferior ganglia of the vagus nerve (nodose ganglia; NG) [Czaja et al., 2006]. These afferents innervate the abdominal viscera [Berthoud \& Powley, 1992; Prechtl \& Powley, 1990] and make their first synapse in the Nucleus Tractus Solitarius (NTS) [Berthoud \& Powley, 1992]. Visceral afferents in the NTS then project upstream to the parabrachial nucleus, the second central relay. Parabrachial nuclei neurons ultimately carry information to the hypothalamus, the amygdala, and the bed nucleus of the stria terminalis [Norgren, 1983]. In addition, NTS neurons project to the dorsal motor nucleus of the vagus (DMV) cells to provide preganglionic control of cholinergic excitatory as well as non- 
adrenergic non-cholinergic inhibitory postganglionic neurons [Broussard \& Altschuler, 2000]. The efferent innervation to the stomach originates from the DMV [Berthoud et al., 1991; Kirchgessner \& Gershon, 1989; Moran et al., 1997] and the majority of DMV neurons project to the myenteric plexus, with the highest density of efferent fibers terminating in the stomach [Berthoud et al., 1991].

Appetite is an intrinsic driving force to search for, choose, and ingest food [De Graaf et al., 2004]. When we eat, a multi-tasking cascade of events is triggered to digest the consumed food and keep the organism informed of the nutrients and amounts being consumed. The gut microbiota plays a significant role in energy and nutrient harvesting as well as maintenance of a healthy mucosal barrier and stimulation of the host's immune system, and disturbances to the intestinal microbiome have been associated with inflammation and obesity [Gawey \& Czaja, 2017; Cox et al., 2015; Sen et al., 2017; Tlaskalová-Hogenová et al., 2011; Vaughn et al., 2017]. In humans, the most abundant bacteria phyla are Bacteroidetes and Firmicutes [Johnson et al., 2017]. Bacteroidetes, also known as the good guys, are associated with production of healthy metabolites, like short-chain fatty acids. In contrast, Firmicutes are gramnegative bacteria typically labelled as the bad guys due to their role in glucose fermentation and its metabolites, mainly butyrate [Ismail et al., 2011]. In healthy individuals, Bacteroidetes are present in greater density than Firmicutes [Chakraborti, 2015].

Diet is a major contributor to changes in the gut microbiome composition [Shoaie et al., 2015]. The underlying cause of obesity is, in its simplest explanation, an increase in caloric intake accompanied by a decrease in physical activity. However, it has been hypothesized that the gut microbiome of obese subjects harbors microbial communities that promote more efficient energy extraction from dietary sources. In recent years, there has been a surge in scientific evidence which shows that there is a correlation between changes in the gut microbiome and obesity. Ley et al. [2005] found that there is a difference in the ratio of Bacteroidetes to Firmicutes where the obese mice exhibit a decrease in Bacteroidetes with a concurrent increase in Firmicutes compared to their lean counterpart. This finding has been further shown in children [Bervoets et al., 2013] and adult human subjects [Turnbaugh et al., 2009].

Studies from our lab and others have shown that consumption of diets high in sugar, high in fat, or both triggers changes in the gut microbiome and favors the microbiota composition associated with an obese phenotype. Sen et al. [2017] showed that in rats, consumption of a high-fat, high sugar diet or a low-fat, high sugar diet led to microbiota dysbiosis characterized by a decrease in bacterial diversity and an increase in the ratio of Firmicutes to Bacteroidetes. This increase in abundance of the Firmicutes phyla was driven by an increase in members of the class Clostridia while consumption of a high sucrose diet led to a significant decrease in abundance of Bacilli. Noting this distinction is of particular importance because Lactobacillus, a member of the class Bacilli, is a known probiotic. However, the Ruminococcaceae and Lachnospiraceae families of the phyla Clostridia have been shown to exist in higher abundance in the gut microbiome of obese subjects [Cho et al., 2012; Gomez-Arango et al., 2016; Kim et al., 2012] and have been further associated with increased body fat accumulation [Duca et al., 2014]. In addition, it was further shown that consumption of a high sugar diet, independent of the fat content, significantly increases lipopolysaccharides levels - known endotoxins - and expression of the pro-inflammatory cytokines IL-6, IL-1 $\beta$, and $\mathrm{TNF} \alpha$ in the cecum [Sen et al., 2017]. In short, consumption of a diet high in sugar leads to gut microbiota dysbiosis, gut inflammation, and impaired gut function.

In addition to microbiota dysbiosis, consumption of high sugar diets leads to reorganization of the gut-brain vagal communication system. The responsiveness of vagal afferents to signals originating in the gut has been shown to be decreased in animals fed a high fat, high sugar diet [Covasa \& Ritter, 1998; Little et al., 2007]. It is thus possible that the density and integrity of these afferents is negatively impacted by the hostile gut microbiome environment induced by these diets. Studies in our laboratory have shown that consumption of a high fat, high sucrose diet significantly decreased in the density of vagal afferents that synapse in the NTS [Sen et al., 2017; Vaughn et al., 2017]. It was further shown that this diet triggered activation of microglia cells, a marker of inflammation, in the NTS [Vaughn et al., 2017]. Thus, diet-driven changes in the gut microbiome disrupt gut-brain vagal communication, trigger brain inflammation, and increase accumulation of fat in the body.

\section{PHYSICAL ACTIVITY: MORE IS BETTER, BUT NOT A SOLUTION}

Besides energy consumption, energy expenditure constitutes the other important factor in the energy balance formula. Divided into occupational and leisure-time, physical activity is the only modifiable variable that affects energy expenditure, and thus body weight [Church et al., 2011]. Physical activity is defined as any bodily movement produced by the skeletal muscles that elevates energy expenditure above basal levels [Katzmarzyk et al, , 2008]. Amongst its many health benefits, increasing physical activity resulting in increased energy expenditure has been shown to have a positive correlation with greater long-term weight loss and maintenance of a lower body weight [Jeffery et al., 2003].

With the growing awareness of the importance of physical activity, efforts have been made to promote physical activity in the United States as well as globally in the past few decades. The second edition of the Physical Activity Guidelines for Americans recommends engaging in physical activity at least $3 \mathrm{~h} / \mathrm{d}$ for children $(3-5 y o), 1 \mathrm{~h} / \mathrm{d}$ for children and adolescents (6-17 yo), and $2.5-5 \mathrm{~h} / \mathrm{w}$ for adults. Following these recommendations, between 2008 and 2016, there was an increase in physical activity in adults, but no change in high school-age children. In $2008, \sim 15 \%$ of women and $22 \%$ of men reported meeting the recommended guidelines for physical activity. This increased to $\sim 19 \%$ and $26 \%$ for women and men, respectively by 2016 . In $2011, \sim 12 \%$ of girls and $30 \%$ of boys met the requirements and there was no change by 2015 [Piercy et al., 2018]. 
Occupation-related physical activity, in contrast, has decreased. Since 1960, occupation-related physical activity has been reduced in intensity due to the shift from good producing and agriculture to service, resulted in a drop of more than 100 calories in the estimated mean daily energy expenditure from work-related physical activity. Since work takes up a large portion of the day, this reduction in occupation-related energy expenditure contributed to the increase mean U.S. body weight over the last 5 decades [Church et al., 2011]. The increased reliance on labor-saving technology, such as using motorized transport instead of walking or cycling, has also contributed to the reduction of physical activity in the general population [Fox \& Hillsdon, 2007].
Nevertheless, increasing physical activity is not the sole answer to curbing the obesity epidemic given that increasing physical activity alone is not effective in treating obesity without a meal plan [Griera et al., 2007].

\section{CONCLUSION}

The reviewed data show that since year 2000 the reduction in sugar consumption slowed down the annual increase of obesity in both the adults and children. While sugar is necessary for a healthy life and the consumption trend is going in the right direction, we still consume more than $300 \%$ of the daily recommended amount of added sugar. These
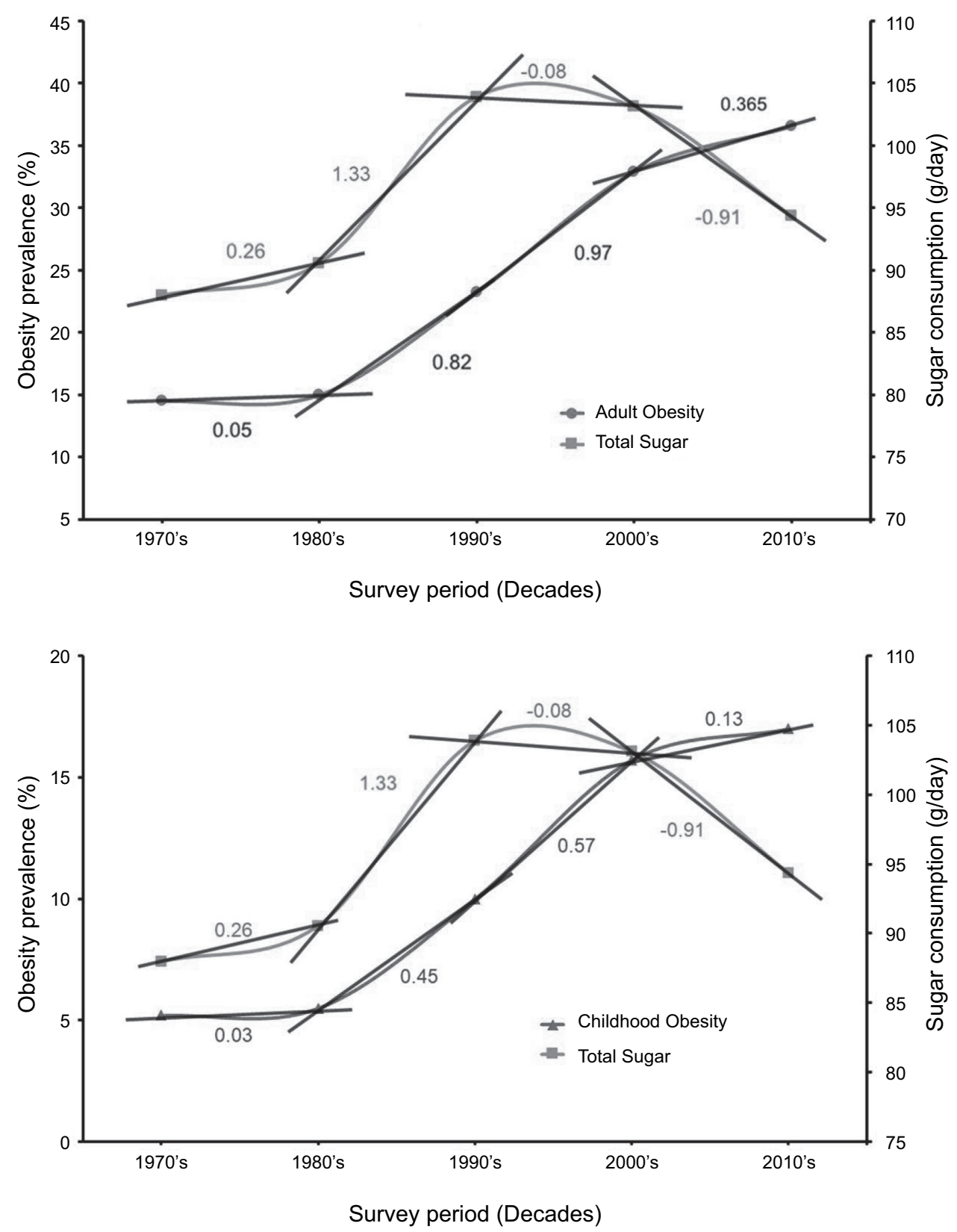

FIGURE 5. Total sugar consumption per decade in g/day compared to obesity prevalence per decade in percent for adults (top panel) and children (bottom panel). The rate of change per year between the decades for both sugar consumption and adult obesity were found by calculating the differences in the average values between each of the decades and dividing it by the number of years elapsed, as indicated by the slope lines and values between the decades. 
trends may describe qualitatively the possible impacts of sugar consumption on rates of change in obesity prevalence, but this analysis is limited by a general lack of consistent data on obesity rates and the absence of statistical analyses and tests possible to better quantify and mathematically indicate the significance of these trends. Future studies can be done to better assess the limited data at hand in order to better determine and measure the described trends. It is important to not single out sugars as the enemy to be avoided at all costs. Sugars are a naturally-occurring, integral component of many unprocessed foods. Most importantly, the brain utilizes the monosaccharide glucose as its primary energy source [Mergenthaler, et al., 2013]. In addition, systematic reviews and meta-analyses of cohort studies and randomized control trials have reported that the link between consumption of AHA-recommended amounts of dietary sugars and obesity does not exist [Khan \& Sievenpiper, 2016; Rippe \& Angelopoulos, 2016; Te Morenga et al., 2012; Khan \& Sievenpiper, 2014]. A positive correlation between sugar consumption and obesity is only apparent when sugar is overconsumed, which is the topic of this review. It is worth recapitulating that obesity is a multifactorial disease. This review focuses on the association between sugar consumption trends and obesity prevalence. However, for a holistic understanding of the causes of obesity, we must also take into account such factors as physical activity, economic status, and consumption of other macronutrients, i.e. fat, and micronutrients, among others. A discussion of all the factors that play a role in the obesity epidemic would be beyond the scope of this review. Nonetheless, this investigation examines these trends using valid and measurable data that hints at the link between sugar consumption and obesity trends and may push further research that considers and further scrutinizes the role of excess sugar and its negative impacts on a population's overall health status.

\section{ACKNOWLEDGEMENTS}

Special thanks to Dr. Steven D. Holladay for proofreading and providing feedback for this paper.

\section{FUNDING SOURCE}

This work was supported by National Institutes of Health, grant no. 5R01DC013904-04.

\section{CONFLICT OF INTERESTS}

All authors declare no conflict of interests.

\section{REFERENCES}

1. Alonso, A.C., Goncalves, T.A., de Almeida, J.K.A., Machado-Lima, A., Ernandes, R.D., Greve, J.M.D., Garcez-Leme, L.E. (2018). Relationship between bone mineral density and body composition in elderly. Acta Ortopedica Brasileira, 26(1), 27-29.

2. Altschuler, S.M., Bao, X., Bieger, D., Hopkins, D.A., Miselis, R.R. (1989). Viscerotopic representation of the upper alimentary tract in the rat: sensory ganglia and nuclei of the solitary and spi- nal trigeminal tracts. Journal of Comparative Neurology, 283(2), 248-268.

3. Archer, E., Hand, G.A., Blair, S.N. (2013). Validity of U.S. Nutritional Surveillance: National Health and Nutrition Examination Survey Caloric Energy Intake Data, 1971-2010. PLoS One, 8(10), art. no. e76632.

4. Baker, J.L., Olsen, L.W., Sørensen, T.I.A. (2007). Childhood body-mass index and the risk of coronary heart disease in adulthood. New England Journal of Medicine, 357(23), 2329-2337.

5. Baranowski, T., Taveras, E.M. (2018). Childhood Obesity Prevention: Changing the Focus: Mary Ann Liebert, Inc., NY, USA.

6. Basciano, H., Federico, L., Adeli, K. (2005). Fructose, insulin resistance, and metabolic dyslipidemia. Nutrition \& Metabolism, 2(1), 5 .

7. Berg, J.M., Tymoczko, J.L., Gatto, G.J., Stryer, L. (2015). Biochemistry: New York: W.H. Freeman \& Company, a Macmillan Education Imprint, $8^{\text {th }}$ ed.

8. Berne, R.M., Koeppen, B.M., Stanton, B.A. (2010). Berne \& Levy Physiology. Philadelphia, PA: Mosby/Elsevier.

9. Berthoud, H.R, Powley, T.L. (1992). Vagal afferent innervation of the rat fundic stomach: morphological characterization of the gastric tension receptor. Journal of Comparative Neurology, 319(2), 261-276.

10. Berthoud, H.R., Carlson, N.R., Powley, T.L. (1991). Topography of efferent vagal innervation of the rat gastrointestinal tract. American Journal of Physiology-Regulatory, Integrative and Comparative Physiology, 260(1), R200-R207.

11. Bervoets, L., Van Hoorenbeeck, K., Kortleven, I., Van Noten, C., Hens, N., Vael, C., Goossens, H., Desager, K.N., Vankerckhoven, V. (2013). Differences in gut microbiota composition between obese and lean children: a cross-sectional study. Gut Pathogens, 5(1), art. no. 10.

12. Blair, D. (1992). Dietary methodology issues related to energy balance measurement for NHANES III. Vital and Health Statistics. Ser. 4, Documents and Committee Reports, (27), 43-50.

13. Bray, G.A., Nielsen, S.J., Popkin, B.M. (2004). Consumption of high-fructose corn syrup in beverages may play a role in the epidemic of obesity. The American Journal of Clinical Nutrition, 79(4), 537-543.

14. Broussard, D.L., Altschuler, S.M. (2000). Brainstem viscerotopic organization of afferents and efferents involved in the control of swallowing. The American Journal of Medicine, 108(4), 79-86.

15. Brownbill, R.A., Ilich, J.Z. (2005). Measuring body composition in overweight individuals by dual energy $\mathrm{x}$-ray absorptiometry. BMC Medical Imaging, 5(1), 1. doi:10.1186/1471-2342-5-1.

16. Brunton, J.A., Bayley, H.S., Atkinson, S.A. (1993). Validation and application of dual-energy $\mathrm{x}$-ray absorptiometry to measure bone mass and body composition in small infants. The American Journal of Clinical Nutrition, 58(6), 839-845.

17. Caprio, S., Genel, M. (2005). Confronting the epidemic of childhood obesity. Pediatrics, 115(2), 494-495.

18. CDC, Center of Disease Control and Prevention. (2012). National Health and Examination Survey. Atlanta, Georgia.

19. CDC, Centers for Disease Control and Prevention. (2016). Defining Adult Overweight and Obesity. Retrieved from [https:// www.cdc.gov/obesity/adult/defining.html].

20. Chakraborti, C.K. (2015). New-found link between microbiota and obesity. World Journal of Gastrointestinal Pathophysiology, 6(4), 110-119. 
21. Cho, I., Yamanishi, S., Cox, L., Methé, B.A., Zavadil, J., Li, K., Gao, Z., Mahana, D., Raju, K., Teitler, I., Li, H., Alekseyenko, A., Blaser, M. (2012). Antibiotics in early life alter the murine colonic microbiome and adiposity. Nature, 488(7413), 621-626.

22. Church, T.S., Thomas, D.M., Tudor-Locke, C., Katzmarzyk, P.T., Earnest, C.P., Rodarte, R.Q., Martin, C.K., Blair, S.N., Bouchard, C. (2011). Trends over 5 decades in U.S. occupationrelated physical activity and their associations with obesity. PLoS ONE, 6(5), art. no. e19657

23. Cote, A.T., Harris, K.C., Panagiotopoulos, C., Sandor, G.G.S., Devlin, A.M. (2013). Childhood obesity and cardiovascular dysfunction. Journal of the American College of Cardiology, 62(15), 1309-1319.

24. Covasa, M., Ritter, R.C. (1998). Rats maintained on high-fat diets exhibit reduced satiety in response to CCK and bombesin. Peptides, 19(8), 1407-1415.

25. Cox, A.J., West, N.P., Cripps, A.W. (2015). Obesity, inflammation, and the gut microbiota. The Lancet Diabetes \& Endocrinology, 3(3), 207-215.

26. Czaja, K., Ritter, R.C., Burns, G.A. (2006). Vagal afferent neurons projecting to the stomach and small intestine exhibit multiple N-methyl-D-aspartate receptor subunit phenotypes. Brain Research, 1119(1), 86-93.

27. Daniels, S.R. (2009). Complications of obesity in children and adolescents. International Journal of Obesity, 33(S1), S60-S65.

28. Deckelbaum, R.J., Williams, C.L. (2001). Childhood obesity: The health issue. Obesity Research, 9(S11), 239S-243S.

29. De Graaf, C., Blom, W.A.M., Smeets, P.A.M., Stafleu, A., Hendriks, H.F.J. (2004). Biomarkers of satiation and satiety. The American Journal of Clinical Nutrition, 79(6), 946-961.

30. Dietz, W.H, Bellizzi, M.C. (1999). Introduction: The use of Body Mass Index to assess obesity in children. The american Journal of Clinical Nutrition, 70, 123S-125S.

31. Do, M., Lee, E., Oh, M.J., Kim, Y., Park, H.Y. (2018). High-glucose or-fructose diet cause changes of the gut microbiota and metabolic disorders in mice without body weight change. Nutrients, 10(6), art. no. 761.

32. Duca, F.A., Sakar, Y., Lepage, P., Devime, F., Langelier, B., Doré, J., Covasa, M. (2014). Replication of obesity and associated signaling pathways through transfer of microbiota from obese-prone rats. Diabetes, 63(5), 1624-1636.

33. Elliott, S.S., Keim, N.L., Stern, J.S., Teff, K., Havel, P.J. (2002). Fructose, weight gain, and the insulin resistance syndrome. The American Journal of Clinical Nutrition, 76(5), 911-922.

34. Fields, D.A., George, B., Williams, M., Whitaker, K., Allison, D.B., Teague, A., Demerath, E.W. (2017). Associations between human breast milk hormones and adipocytokines and infant growth and body composition in the first 6 months of life. Pediatric Obesity, 12(S1), 78-85.

35. Flegal, K.M., Carroll, M.D., Ogden, C.L., Curtin, L.R. (2010). Prevalence and trends in obesity among us adults, 1999-2008. JAMA, 303(3), 235-241.

36. Flegal, K.M., Kruszon-Moran, D., Carroll, M.D., Fryar, C.D., Ogden, C.L. (2016). Trends in obesity among adults in the United States, 2005 to 2014. JAMA, 315(21), 2284-2291.

37. Fox, K.R., Hillsdon, M., (2007). Physical activity and obesity. Obesity Reviews, 8, 115-121.

38. Fryar, C.D., Carroll, M.D., Ogden, C.L. (2014). Prevalence of overweight and obesity among children and adolescents: Unit- ed States, 1963-1965 through 2011-2012. Atlanta, GA: National Center for Health Statistics.

39. Fryar, C.D., Carroll, M.D., Ogden, C.L. (2016). Prevalence of overweight, obesity, and extreme obesity among adults aged 20 and over: United States, 1960-1962 through 2013-2014. National Center for Health Statistics Data, Health E-Stats.

40. Gawey, B., Czaja, K. (2017). Broad-spectrum antibiotic abuse and its connections to obesity. Journal of Nutritional Health and Food Science, 5(4), 1-21.

41. Gomez-Arango, L.F., Barrett, H.L., McIntyre, H.D., Callaway, L.K., Morrison, M., Nitert, M.D. (2016). Connections between the gut microbiome and metabolic hormones in early pregnancy in overweight and obese women. Diabetes, 65(8), 2214-2223.

42. Goran, M.I. (1998). Measurement issues related to studies of childhood obesity: assessment of body composition, body fat distribution, physical activity, and food intake. Pediatrics, 101 (Supplement 2), 505-518.

43. Griera, J.L., Manzanares, J.M., Barbany, M., Contreras, J., Amigó, P., Salas-Salvadó, J. (2007). Physical activity, energy balance and obesity. Public Health Nutrition, 10(10A), 1194-1199.

44. Haley, S.E., Reed, J.E., Lin, B.H., Cook, A. (2005). Sweetener consumption in the United States: distribution by demographic and product characteristics. ERS Outlook Report Series, 1-19.

45. Havel, P.J. (2005). Dietary fructose: implications for dysregulation of energy homeostasis and lipid/carbohydrate metabolism. Nutrition Reviews, 63(5), 133-157.

46. Hu, F.B. (2008). Measurements of adiposity and body composition. In F.B. Hu Obesity Epidemiology, Chapter 4, Oxford University Press, pp. 53-83.

47. Ismail, N.A., Ragab, S.H., ElBaky, A.A., Shoeib, A.R.S., Alhosary, Y., Fekry, D. (2011). Frequency of Firmicutes and Bacteroidetes in gut microbiota in obese and normal weight Egyptian children and adults. Archives of Medical Science: AMS, 7(3), 501-507.

48. Jeffery, R.W., Wing, R.R., Sherwood, N.E., Tate, D.F. (2003). Physical activity and weight loss: does prescribing higher physical activity goals improve outcome?. The American Journal of Clinical Nutrition, 78(4), 684-689.

49. Johnson, E.L., Heaver, S.L., Walters, W.A., Ley, R.E. (2017). Microbiome and metabolic disease: revisiting the bacterial phylum Bacteroidetes. Journal of Molecular Medicine, 95(1), 1-8.

50. Johnson, R.K., Appel, L.J., Brands, M., Howard, B.V., Lefevre, M., Lustig, R.H., Sacks, F., Steffen, L.M., Wylie-Rosett, J. (2009). Dietary sugars intake and cardiovascular health: a scientific statement from the American Heart Association. Circulation, 120(11), 1011-1020.

51. Kantor, L.S., Lipton, K., Manchester, A., Oliveira, V. (1997). Estimating and addressing America's food losses. Food Review: The Magazine of Food Economics, 20(1482-2016-121447), $2-12$.

52. Kahn, R., Sievenpiper, J.L. (2014). Dietary sugar and body weight: Have we reached a crisis in the epidemic of obesity and diabetes? We have, but the pox on sugar is overwrought and overworked. Diabetes Care, 37(4), 957-962.

53. Khan, T.A., Sievenpiper, J.L. (2016). Controversies about sugar: results from systematic reviews and meta-analyses on obesity, cardiometabolic disease and diabetes. European Journal of Nutrition, 55(Suppl. 2), 25-43.

54. Katzmarzyk, P.T., Baur, L.A., Blair, S.N., Lambert, E.V., Oppert, J.M., Riddoch, C. (2008). International conference on physical 
activity and obesity in children: summary statement and recommendations. International Journal of Pediatric Obesity, 3(1), 3-21.

55. Kim, K., Gu, W., Lee, I., Joh, E., Kim, D. (2012). High fat diet-induced gut microbiota exacerbates inflammation and obesity in mice via the TLR4 signaling pathway. PLOS ONE, 7(10), art. no. e47713.

56. Kirchgessner, A.L., Gershon, M.D. (1989). Identification of vagal efferent fibers and putative target neurons in the enteric nervous system of the rat. Journal of Comparative Neurology, 285(1), 38-53.

57. Kuczmarski, R.J. (2002). 2000 CDC growth charts for the United States; methods and development, [https://stacks.cdc.gov/ view/cdc/6451].

58. Levin, R.J. (1994). Digestion and absorption of carbohydrates from molecules and membranes to humans. The American Journal of Clinical Nutrition, 59(suppl.), 690S-698S.

59. Ley, R.E., Bäckhed, F., Turnbaugh, P., Lozupone, C.A., Knight, R.D., Gordon, J.I. (2005). Obesity alters gut microbial ecology. Proceedings of the National Academy of Sciences, 102(31), 11070-11075 .

60. Little, T.J., Horowitz, M., Feinle-Bisset, C. (2007). Modulation by high-fat diets of gastrointestinal function and hormones associated with the regulation of energy intake: implications for the pathophysiology of obesity. The American Journal of Clinical Nutrition, 86(3), 531-541.

61. Liu, Y., Tong, G., Tong, W., Lu, L., Qin, X. (2011). Can body mass index, waist circumference, waist-hip ratio and waist-height ratio predict the presence of multiple metabolic risk factors in Chinese subjects? BMC Public Health, 11, 35-35.

62. Lohman, T.G. (1986). Applicability of body composition techniques and constants for children and youths. Exercise and Sport Sciences Reviews, 14, 325-358.

63. Ludwig, D.S., Peterson, K.E., Gortmaker, S.L. (2001). Relation between consumption of sugar-sweetened drinks and childhood obesity: a prospective, observational analysis. The Lancet, 357(9255), 505-508.

64. Malik, V.S., Schulze, M.B., Hu, F.B. (2006). Intake of sugarsweetened beverages and weight gain: a systematic review. The American Journal of Clinical Nutrition, 84(2), 274-288.

65. Marieb, E.N. (2001). Human Anatomy \& Physiology: San Francisco: Benjamin Cummings, $5^{\text {th }}$ ed.

66. Marteau, T.M., Hollands, G.J., Shemilt, I., Jebb, S.A. (2015). Downsizing: policy options to reduce portion sizes to help tackle obesity. BMJ, 351, art. no. h5863.

67. Miftahof, R.N. (2017). Biomechanics of the Human Stomach. [electronic resource]: Cham : Springer International Publishing: Imprint: Springer.

68. Mergenthaler, P., Lindauer, U., Dienel, G.A., Meisel, A. (2013). Sugar for the brain: the role of glucose in physiological and pathological brain function. Trends in Neurosciences, 36(10), 587-597.

69. Moran, T.H., Baldessarini, A.R., Salorio, C.F., Lowery, T., Schwartz, G.J. (1997). Vagal afferent and efferent contributions to the inhibition of food intake by cholecystokinin. American Journal of Physiology-Regulatory, Integrative and Comparative Physiology, 272(4), R1245-R1251.

70. Morris, M.J., Beilharz, J.E., Maniam, J., Reichelt, A.C., Westbrook, R.F. (2015). Why is obesity such a problem in the $21 \mathrm{st}$ century? The intersection of palatable food, cues and reward pathways, stress, and cognition. Neuroscience \& Biobehavioral Reviews, 58, 36-45.
71. National Heart, Lung, and Blood Institute. (2013). According to Waist Circumference. Retrieved from [https://www.nhlbi.nih. gov/health-pro/guidelines/current/obesity-guidelines/e_textbook/txgd/4142.htm].

72. Norgren, R. (1983). Afferent interactions of cranial nerves involved in ingestion. Journal of the Autonomic Nervous System, 9(1), 67-77.

73. Ogden, C.L., Carroll, M.D. (2010). Prevalence of overweight, obesity, and extreme obesity among adults: United States, trends 1960-1962 through 2007-2008. National Center for Health Statistics, 6(1), 1-6.

74. Ogden, C.L., Carroll, M.D., Lawman, H.G., Fryar, C.D., Kruszon-Moran, D., Kit, B.K., Flegal, K.M., (2016). Trends in obesity prevalence among children and adolescents in the United States, 1988-1994 through 2013-2014. JAMA, 315(21), 2292-2299.

75. Ouchi, N., Parker, J.L., Lugus, J.J., Walsh, K. (2011). Adipokines in inflammation and metabolic disease. Nature Reviews Immunology, 11(2), 85-97.

76. Piercy, K.L., Troiano, R.P., Ballard, R.M., Carlson, S.A., Fulton, J.E., Galuska, D.A., George, S.M., Olson, R.D. (2018). The physical activity guidelines for americans. JAMA, 320(19), 2020-2028.

77. Poonawalla, A.H., Sjoberg, B.P., Rehm, J.L., Hernando, D., Hines, C.D., Irarrazaval, P., Reeder, S.B. (2013). Adipose tissue MRI for quantitative measurement of central obesity. Journal of Magnetic Resonance Imaging, 37(3), 707-716.

78. Prechtl, J.C., Powley, T.L. (1990). The fiber composition of the abdominal vagus of the rat. Anatomy and Embryology, 181(2), 101-115.

79. Raushel, F.M., Cleland, W.W. (1973). The substrate and anomeric specificity of fructokinase. The Journal of Biological Chemistry, 248(23), 8174-8177.

80. Reilly, J.J., Methven, E., McDowell, Z.C., Hacking, B., Alexander, D., Steward, L., Kelnar, C.J.H. (2003). Health consequences of obesity. Archives of Disease in Childhood, 88(9), 748-752

81. Rippe, J.M., Angelopoulos, T.J. (2016). Sugars, obesity, and cardiovascular disease: results from recent randomized control trials. European Journal of Nutrition, 55(S2), 45-53.

82. Ritter, R.C. (2004). Gastrointestinal mechanisms of satiation for food. Physiology \& Behavior, 81 (2), 249-273.

83. Rokholm, B., Baker, J.L., Sørensen, T.I.A. (2010). The levelling off of the obesity epidemic since the year 1999-a review of evidence and perspectives. Obesity Reviews, 11(12), 835-846.

84. Romero-Corral, A., Somers, V.K., Sierra-Johnson, J., Thomas, R.J., Collazo-Clavell, M.L., Korinek, J., Allison, T.G., Batsis, J.A., Sert-Kuniypshi, F.H., Lopez-Jimenez, F. (2008). Accuracy of body mass index in diagnosing obesity in the adult general population. International Journal of Obesity, 32 (6), 959-966.

85. Rothman, K.J. (2008). BMI-related errors in the measurement of obesity. International Journal of Obesity, 32, S56-S59.

86. Rothney, M.P., Brychta, R.J., Schaefer, E.V., Chen, K.Y., Skarulis, M.C. (2009). Body composition measured by dual-energy x-ray absorptiometry half-body scans in obese adults. Obesity (Silver Spring, Md.), 17(6), 1281-1286.

87. Ruderman, N., Chisholm, D., Pi-Sunyer, X., Schneider, S. (1998). The metabolically obese, normal-weight individual revisited. Diabetes, 47(5), 699-713.

88. Saha, P., Manoharan, P., Arthur, S., Sundaram, S., Kekuda, R., Sundaram, U. (2015). Molecular mechanism of regulation of vil- 
lus cell Na-K-ATPase in the chronically inflamed mammalian small intestine. Biochimica et Biophysica Acta (BBA) - Biomembranes, $1848(2), 702-711$.

89. Sarria, A., Garcia-Llop, L.A., Moreno, LA., Fleta, J., Morellon, M.P., Bueno, M. (1998). Skinfold thickness measurements are better predictors of body fat percentage than body mass index in male Spanish children and adolescents. European Journal of Clinical Nutrition, 52(8), 573-576.

90. Schulze, M.B., Manson, J.E., Ludwig, D.S., Colditz, G.A., Stampfer, M.J., Willett, WC., Hu, FB. (2004). Sugar-sweetened beverages, weight gain, and incidence of type 2 diabetes in young and middle-aged women. JAMA, 292(8), 927-934.

91. Schwartz, G.J. (2000). The role of gastrointestinal vagal afferents in the control of food intake: current prospects. Nutrition, 16(10), 866-873.

92. Seidell, J.C., Halberstadt, J. (2016). Obesity: The obesity epidemic in the USA-no end in sight? Nature Reviews Endocrinology, 12(9), 499-500.

93. Sen, T., Cawthon, C.R., Ihde, B.T., Hajnal, A., DiLorenzo, P.M., de la Serre, C.B., Czaja, K. (2017). Diet-driven microbiota dysbiosis is associated with vagal remodeling and obesity. Physiology \& Behavior, 173, 305-317.

94. Shoaie, S., Ghaffari, P., Kovatcheva-Datchary, P., Mardinoglu, A., Sen, P., Pujos-Guillot, E., de Wouters, T., Juste, C., Rizkalla, S., Chilloux, J., Hoyles, L., Nicholson, J.K., Consortium MICRO-Obes., Dore, J., Dumas, M.E., Clement, K., Backhed, F., Nielsen, J. (2015). Quantifying diet-induced metabolic changes of the human gut microbiome. Cell Metabolism, 22(2), 320-331.

95. Silver, H.J., Welch, E.B., Avison, M.J., Niswender, K.D. (2010). Imaging body composition in obesity and weight loss: challenges and opportunities. Diabetes, Metabolic Syndrome and Obesity: Targets and Therapy, 3, 337-347.

96. Skinner, A.C., Perrin, E.M., Moss, L.A., Skelton, J.A. (2015). Cardiometabolic risks and severity of obesity in children and young adults. New England Journal of Medicine, 373(14), 1307-1317.

97. Stanhope, K.L., Schwarz, J.M., Havel, P.J. (2013). Adverse metabolic effects of dietary fructose: results from recent epidemiological, clinical, and mechanistic studies. Current Opinion in Lipidology, 24(3), 198-206.

98. Stanhope, K.L., Schwarz, J.M., Keim, N.L., Griffen, S.C., Bremer, A.A., Graham, J.L., Hatcher, B., Cox, C.L., Dyachenko, A., Zhang, W., McGahan, J.P., Seibert, A., Krauss, R.M., Chiu, S., Schaefer, E.J., Ai, M., Otokozawa, S., Nakajima, K., Nakano, T., Beysen, C., Hellerstein, M.K., Berglund, L., Havel, P.J. (2009). Consuming fructose-sweetened, not glucosesweetened, beverages increases visceral adiposity and lipids and decreases insulin sensitivity in overweight/obese humans. The Journal of Clinical Investigation, 119(5), 1322-1334.

99. Stenesh, J., Stenesh, J. (1989). Dictionary of Biochemistry and Molecular Biology, $2^{\text {nd }}$ edition. Wiley, New York.

100. Talma, H., Chinapaw, M.J.M., Bakker, B., HiraSing, R.A., Terwee, C.B., Altenburg, T.M. (2013). Bioelectrical impedance analysis to estimate body composition in children and adolescents: a systematic review and evidence appraisal of validity, responsiveness, reliability and measurement error. Obesity Reviews, 14(11), 895-905.

101. Te Morenga, L., Mallard, S., Mann, J. (2013). Dietary sugars and body weight: systematic review and meta-analyses of randomised controlled trials and cohort studies. BMJ, 346, art. no. e7492.

102. Tlaskalová-Hogenová, H., Štěpánková, R., Kozáková, H., Hudcovic, T., Vannucci, L., Tučková, L., Rossman, P., Hrncir, T., Kverka, M., Zákostelská, Z., Klimesova, K., Pribylova, J., Bartova, J., Sanchez, D., Fundova, P., Borovska, D., Srutkova, D., Zidek, Z., Schwarzer, M., Drastich, P., Funda, D.P. (2011). The role of gut microbiota (commensal bacteria) and the mucosal barrier in the pathogenesis of inflammatory and autoimmune diseases and cancer: contribution of germ-free and gnotobiotic animal models of human diseases. Cellular \& Molecular Immunology, 8(2), 110-120.

103. Trowbridge, F.L., Marks, J.S., de Romaña, G.L., Madrid, S., Boutton, T.W., Klein, P.D. (1987). Body composition of Peruvian children with short stature and high weight-for-height. II. Implications for the interpretation for weight-for-height as an indicator of nutritional status. The American Journal of Clinical Nutrition, 46(3), 411-418.

104. Turnbaugh, P.J., Hamady, M., Yatsunenko, T., Cantarel, B.L., Duncan, A., Ley, R.E., Sogin, M.L., Jones, W.J., Roe, BA., Affortit, J.P., Egholm, M., Henrissat, B., Heath, AC., Knight, R., Gordon, J.I. (2009). A core gut microbiome in obese and lean twins. Nature, 457(7228), 480-484.

105. USDA, ERS. (2017). Sugar and Sweeteners Outlook.

106. Vaughn, A.C., Cooper, E.M., DiLorenzo, P.M., O'Loughlin, L.J., Konkel, M.E., Peters, J.H., Hajnal, A., Sen, T., Lee, S.H., de La Serre, C.B., Czaja, K. (2017). Energy-dense diet triggers changes in gut microbiota, reorganization of gut-brain vagal communication and increases body fat accumulation. Acta Neurobiologiae Experimentalis, 77(1), 18-30.

107. Waters, E., de Silva-Sanigorski, A., Burford, B.J., Brown, T., Campbell, K.J., Gao, Y., Prosser, L., Summerbell, C.D. (2011). Interventions for preventing obesity in children. Cochrane Database of Systematic Reviews, 7(12), art. no. CD001871.

108. Watson, R.R. (2014). Nutrition in the Prevention and Treatment of Abdominal Obesity: Amsterdam : Elsevier/Academic Press.

109. WHO, World Health Organization (1948). Manual of The International Statistical Classification of Diseases, Injuries, and Causes of Death: Sixth Revision of the International Lists of Diseases and Causes of Death, adopted 1948.

110. WHO, World Health Organization. (2011). Waist Circumference and Waist-Hip Ratio: Report of a WHO Expert Consultation, Geneva, 8-11 December 2008.

Received: 13 March 2019. Revised: 10 June 2019. Accepted: 16 July 2019. Published on-line: 21 August 2019. 
